\title{
Relative children's lipid accumulation with hypertension in Chinese children and adolescents
}

\author{
Zizhe Zhang, Li Zhang, Lili Sun, Bangxuan Wang, Yongting Yuan, Huaiquan Gao and Lianguo Fu*
}

\begin{abstract}
Background: This study aimed to develop a novel indicator associated with hypertension in Chinese children and adolescents, the relative children's lipid accumulation product (RCLAP).

Methods: A cross-sectional study was conducted in 2018. A total of 683 students aged 8-15 years were recruited via a stratified cluster sampling Methods. Anthropometric indexes (waist circumference (WC), Body mass index (BMI), Waist-height ratio (WHtR), logarithm children LAP (LnCLAP), RCLAP per height (RCLAP-H)) were standardized using a z-score method (standardized variables: SWC, SBMI, SWHtR, SLnCLAP, SRCLAP-H). A logistic regression model was performed to evaluate the association of the above indicators with the outcome of hypertension.

Results: The overall prevalence of hypertension was $5.7 \%$ (5.5\% in boys, $6.0 \%$ in girls). SWC $\geq P_{75}, \mathrm{SBMI} \geq P_{75}$, SWHtR $\geq P_{75}$, SInCLAP $\geq P_{75}$ and SRCLAP-H $\geq P_{75}$ significantly increased risk of hypertension, with odds ratios (OR) of 2.21 (95\% confidence interval (Cl): 1.13, 4.30), 2.30 (1.18, 4.49), 2.64 (1.35, 5.14), $4.43(2.28,8.61)$, and $4.49(2.31,8.71)$, respectively.

Conclusion: RCLAP is a novel indicator associated with hypertension in Chinese children and adolescents, and it performs better than WC, BMI, WHtR and children LAP.
\end{abstract}

Keywords: Hypertension, children's lipid accumulation product, Children and adolescents

\section{Introduction}

Hypertension is the most common risk factor for cardiovascular disease (CVD) morbidity and mortality, and it has been found to be seriously harmful to human health worldwide [1,2]. Childhood hypertension was once considered a rare disease, but it is now a major public health problem worldwide [3-6]. A meta-analysis of 25 studies showed that the prevalence of hypertension among 943,128 17-year-olds increased steadily from $6.3 \%$ in 1995 to $19.2 \%$ in 2014 [7]. The Health and Nutrition Survey of Chinese residents reported that the prevalence

* Correspondence: 935677399@qq.com; lianguofu@163.com Department of child and adolescent health, School of public health, Bengbu Medical College, No. 2600 east sea avenue, Room 207, Bengbu 233030, Anhui, China

\section{$\mathrm{BMC}$}

(C) The Author(s). 2021 Open Access This article is licensed under a Creative Commons Attribution 4.0 International License, which permits use, sharing, adaptation, distribution and reproduction in any medium or format, as long as you give appropriate credit to the original author(s) and the source, provide a link to the Creative Commons licence, and indicate if changes were made. The images or other third party material in this article are included in the article's Creative Commons licence, unless indicated otherwise in a credit line to the material. If material is not included in the article's Creative Commons licence and your intended use is not permitted by statutory regulation or exceeds the permitted use, you will need to obtain permission directly from the copyright holder. To view a copy of this licence, visit http://creativecommons.org/licenses/by/4.0/ The Creative Commons Public Domain Dedication waiver (http://creativecommons.org/publicdomain/zero/1.0/) applies to the data made available in this article, unless otherwise stated in a credit line to the data. 
Traditionally, the body mass index (BMI), waist-toheight ratio (WHtR) and triglycerides (TG) are the most commonly used indicators to evaluate overall obesity and abdominal obesity in children [15]. However, BMI can only reflect the degree of overweight, but not the fat distribution of the individual. Abdominal fat is more closely related to hypertension than BMI $[16,17]$. Although the waist circumference (WC) and WHtR can accurately reflect the degree of abdominal obesity, they cannot distinguish between subcutaneous fat and visceral fat. In addition, a prospective study reported a significant relationship between TG and hypertension [18], but triglycerides were limited to showing adipose tissue accumulation.

In 2005, Kahn et al. [19] put forward the concept of the lipid accumulation product (LAP) for the first time and combined the WC and TG to estimate excessive lipid accumulation in adults. It was found that association between LAP and diabetes was stronger than that between BMI and diabetes in adults [19]. Increasing numbers of studies have shown that LAP has a stronger association with hypertension than other obesity indicators in adults [20-22].

Due to their characteristics of rapid growth and development, LAP cannot be directly used to reflect the lipid accumulation of children and adolescents. Our previous study developed a new indicator, the children lipid accumulation product (children LAP), and confirmed that children LAP was significantly associated with metabolic syndrome and hypertension in children [23, 24]. The children LAP is the product of $\mathrm{WC}$, TG and abdominal skinfold thickness (AST) (children LAP $=\mathrm{WC}(\mathrm{cm}) \times$ AST $(\mathrm{mm}) \times$ TG $(\mathrm{mmol} / \mathrm{L}) / 100)$. However, children LAP is limited to reflecting lipid accumulation per unit density of the body. The relative children LAP per unit body height may better reflect the density of lipid accumulation among children and adolescents. This study aimed to evaluate the association of relative children's lipid accumulation product (RCLAP) with hypertension in Chinese children and adolescents.

\section{Methods}

\section{Study participants}

In this study, a cross-sectional survey among students aged 8-15 years from two nine-year-system schools in Bengbu was conducted in 2018. A total of 683 students (366 boys (53.6\%) and 317 girls $(46.4 \%)$ ) were selected by stratified cluster sampling. The study was conducted in accordance with the Declaration of Helsinki (as revised in 2013). The present study was approved by the Medical Ethics Committee of Bengbu Medical College [2015 No. 003] and informed consent was taken from all the participants (or their parents) before the survey.

\section{Data collection and measurements Anthropometric indices}

The medical staff who received standardized training measured the participants' body weight, height, sitting height (SH), WC, and AST [23]. The participants were required to have an empty stomach, wear light clothes, and be barefoot when measured. Body height and $\mathrm{SH}$ were measured using a mechanical height gauge with an accuracy of $0.1 \mathrm{~cm}$. Weight was measured using an electronic weight scale with an accuracy of $0.1 \mathrm{~kg}$. The WC that was the perimeter of the $\mathrm{WC}$ at $1 \mathrm{~cm}$ above the belly button was measured using nylon tape with an accuracy of $0.1 \mathrm{~cm}$. The AST, which was the skinfold thickness at the junction of the right collarbone midline and belly button horizontal line, was measured using a skinfold thickness gauge with an accuracy of $0.1 \mathrm{~mm}$.

\section{Dietary behaviors and physical activity indices}

A self-administered food frequency questionnaire was used to investigate dietary behaviors, including breakfast frequency, eggs, milk, fresh vegetables, fruits, nuts, eating out, fried food, carbonated drinks, western fast food, high-energy snacks $[23,24]$. The scores of each dietary behavior were as follows: 7 points (7 times / week), 5 points (4 times / week), 2 points (1 time / week), 0.5 points ( 2 times / month), 0.25 points ( 1 time / month) and 0 points (never). Eating behaviors were divided into healthy and unhealthy dietary behaviors (healthy dietary behaviors including breakfast, eggs, milk, fresh vegetables, fruits, nuts; unhealthy dietary behaviors including eating out, fried foods, carbonated drinks, Western fast food, high-energy snacks). The total scores of healthy eating behaviors and unhealthy eating behaviors were calculated. Cronbach's alpha coefficients of healthy dietary behaviors and unhealthy dietary behaviors scores were 0.705 and 0.700 , respectively. According to the 75th percentile $\left(P_{75}\right)$ of participants with healthy eating behaviors were divided into $\geq P_{75}$ group and $<P_{75}$ group. According to the 75 th percentile $\left(P_{75}\right)$ of participants with unhealthy eating behaviors were divided into $\geq P_{75}$ group and $<P_{75}$ group. The Chinese Children's Leisure Activities Study Survey questionnaire (CLASS-C) [25] was used to investigate the time of moderate to severe physical activity and sedentary activity. The time of moderate or strenuous exercise was divided into two grades: $\geq 60 \mathrm{~min}$ and $<60 \mathrm{~min}$ [26]. The time of sedentary activity was divided into two levels: $\geq 120 \mathrm{~min}$ and $<$ $120 \mathrm{~min}$ [27].

\section{Blood lipid measurements}

Three milliliters of fasting venous blood were collected from each student at the physical examination center of a grade III, class A hospital. The collected blood samples were centrifuged within $2 \mathrm{~h}$ and TG $(\mathrm{mmol} / \mathrm{L})$ was 
detected by an enzymatic method using an automated biochemical analyzer.

\section{Blood pressure measurement}

After having a rest for at least $10 \mathrm{~min}$, appropriate cuffs were selected according to age and arm circumference of the subjects, and the systolic blood pressure (SBP) and diastolic blood pressure (DBP) on the right arm were measured using a mercury sphygmomanometer. SBP was defined as the onset of the Korotkoff sound (K1), and DBP was defined as the fifth Korotkoff sound (K5). The blood pressure was measured at an interval of $2 \mathrm{~min}$, and the average of the two measurements was recorded as the final blood pressure value.

\section{Definition of hypertension}

In this study, hypertension was diagnosed according to "Reference of screening for elevated blood pressure among Chinese children and adolescents aged 7-18 years" (Health industry standard of the People's Republic of China: WS/T 610-2018) [28].

\section{Calculation of derivative indicators}

BMI $=$ weight $(\mathrm{kg}) /$ height $^{2}\left(\mathrm{~m}^{2}\right) ; \mathrm{WHtR}=\mathrm{WC}(\mathrm{cm}) /$ height $(\mathrm{cm})$; Children LAP $=$ WC $(\mathrm{cm}) \times \operatorname{AST}(\mathrm{mm}) \times$ TG (mmol/L) / 100. Relative children's lipid accumulation product per height $(\mathrm{RCLAP}-\mathrm{H})=\mathrm{WC}(\mathrm{cm}) \times \mathrm{AST}$ $(\mathrm{mm}) \times \mathrm{TG}(\mathrm{mmol} / \mathrm{L}) /$ height $(\mathrm{cm})$.

\section{Statistical analysis}

The sample size was determined according to the crosssectional design of the current situation. The calculation formula was $n=\frac{\mu_{\alpha / 2}^{2} p(1-p)}{\delta^{2}}$ (where $\alpha=0.05, \delta=0.03$, and $p$ is the prevalence of hypertension). A study showed that the prevalence of hypertension in children aged 6-13 years in China was 18.4\% [29]. According to the formula of sample size, the sample size should be 641(641= $1.96 \times 1.96 \times 0.184 \times(1-0.184) / 0.03 / 0.03)$, however, the $5 \%$ of sample size needed to be increased for sampling error. Therefore, the minimum sample size was 673 $(673=641 \times(1+1.05))$. In fact, the effective sample size was 683. SPSS 23.0 software was used for statistical analysis. The measurement and counting data are described by average with $95 \%$ confidence interval $(\mathrm{CI})$ and ratio or proportion, respectively. Logarithm Children LAP (LnCLAP), RCLAP-H, height, weight, SH, WC, WHtR, BMI, AST and TG were standardized by sex and age using z-scores (standardized variables: SLnCLAP, SRCLAP-H, Sheight, Sweight, SSH, SWC, SWHtR, SBMI, SAST and STG). T-tests was used to compare the differences in above standardized indices between children with hypertension and non-hypertension. Chisquare tests were used to analyze associations between above standardized indices and hypertension. Furthermore, after adjusting for moderate-to-vigorous physical activity time, sedentary activity time, healthy dietary behaviors and risky dietary behaviors, the logistic regression models were used to analyse the relations between anthropometric indexes and hypertension.

\section{Results}

The overall prevalence of hypertension was 5.7\% (5.5\% for boys and $6.0 \%$ for girls). From Table 1, we see that SSH, Sweight, SWC, SAST, STG, SBMI, SWHtR, SlnCLAP and SRCLAP-H were significantly lower in non-hypertensive children than they were in hypertensive children $(P<0.05)$. The mean difference in standardized units of two groups with $95 \%$ CI of Sheight, SSH, Sweight, SWC, SAST, STG, SBMI, SWHtR, SlnCLAP and SRCLAP-H were -0.17 ($0.49,0.15),-0.33(-0.65,-0.01),-0.32(-0.64,-0.01)$, $0.59(-0.98,-0.2),-0.69(-1.00,-0.37),-0.43(-0.85,-$ $0.02),-0.32(-0.64,0.00),-0.59(-1.02,-0.15),-0.64(-$ $0.96,-0.33)$ and $-0.83(-1.29,-0.37)$, respectively.

As shown in Table 2. The moderate-to-vigorous physical activity time, sedentary activity time, healthy dietary behaviors and unhealthy dietary behaviors were not significantly related to hypertension in these children $(P>$ 0.05). There was no significant difference in Sheight and SSH between hypertensive and non-hypertensive children $(P>0.05)$. The results of chi-square test showed that Sweight, SWC, SAST, STG, SBMI, SWHtR, SlnCLAP and SRCLAP-H were significantly associated with hypertension in sample children $(P<0.05)$.

As shown in Table 3, Logistic models of the relationship between anthropometric indices and hypertension were setted up. After adjusting for moderate-to-vigorous physical activity time, sedentary activity time, healthy dietary behaviors and risky dietary behaviors, then factors Sweight, SWC, SAST, STG, SBMI, SWHtR, SlnCLAP and SRCLAP-H were separately entered into the logistic regression models as covariates. The results of the logistic regression models showed that the z-sores $\geq P_{75}$ groups of Sweight, SWC, SAST, STG, SBMI, SWHtR, SlnCLAP and SRCLAP-H were significantly associated with an increased risk of hypertension in children $(P<0.05)$, with odds ratios $(\mathrm{OR})$ of $1.99(95 \% \mathrm{CI}$ : $1.02,3.91), 2.21$ (1.13, 4.30), 3.61 (1.86, 6.99), 2.43 (1.25, 4.71), 2.30 (1.18, 4.49), 2.64 (1.35, 5.14), 4.43 (2.28, 8.61), and $4.49(2.31,8.71)$, respectively. In addition, Sweight, SWC, SAST, STG, SBMI, SWHtR, SlnCLAP and SRCLAP-H as independent variables were put into logistic model, after adjusting for moderate-to-vigorous physical activity time, sedentary activity time, healthy dietary behaviors and risky dietary behaviors, the result of stepwise logistic model (forward conditional method) showed only SRCLAP-H $\geq P_{75}$ significantly increased risk of hypertension $(\mathrm{OR}(95 \% \mathrm{CI})=4.49(2.31,8.71))$. 
Table 1 Differences in standardized anthropometric indexes in children with hypertension and non-hypertension. $(n=683)$

\begin{tabular}{|c|c|c|c|c|}
\hline Variables & $\begin{array}{l}\text { Non-hypertension } \\
\text { Group }(n=644) \\
\text { Mean }(95 \% C l)\end{array}$ & $\begin{array}{l}\text { Hypertension } \\
\text { Group }(n=39) \\
\text { Mean }(95 \% \mathrm{Cl})\end{array}$ & $\begin{array}{l}\text { Mean Difference } \\
\text { Mean }(95 \% \mathrm{Cl})\end{array}$ & $P$-value \\
\hline Sheight & $-0.01(-0.09,0.07)$ & $0.16(-0.13,0.45)$ & $-0.17(-0.49,0.15)$ & 0.300 \\
\hline $\mathrm{SSH}$ & $-0.02(-0.10,0.06)$ & $0.31(0.00,0.62)$ & $-0.33(-0.65,-0.01)$ & 0.044 \\
\hline Sweight & $-0.02(-0.10,0.06)$ & $0.31(0.02,0.59)$ & $-0.32(-0.64,-0.01)$ & 0.047 \\
\hline SWC & $-0.03(-0.11,0.04)$ & $0.56(0.17,0.94)$ & $-0.59(-0.98,-0.2)$ & 0.004 \\
\hline SAST & $-0.04(-0.11,0.04)$ & $0.65(0.30,1.00)$ & $-0.69(-1.00,-0.37)$ & $<0.001$ \\
\hline STG & $-0.02(-0.10,0.05)$ & $0.41(0.00,0.82)$ & $-0.43(-0.85,-0.02)$ & 0.043 \\
\hline SBMI & $-0.02(-0.09,0.06)$ & $0.30(-0.04,0.65)$ & $-0.32(-0.64,0.00)$ & 0.048 \\
\hline $\mathrm{SWHtR}$ & $-0.03(-0.11,0.04)$ & $0.55(0.13,0.98)$ & $-0.59(-1.02,-0.15)$ & 0.009 \\
\hline SLnCLAP & $-0.04(-0.11,0.04)$ & $0.61(0.26,0.95)$ & $-0.64(-0.96,-0.33)$ & $<0.001$ \\
\hline SRCLAP-H & $-0.05(-0.12,0.03)$ & $0.79(0.33,1.24)$ & $-0.83(-1.29,-0.37)$ & 0.001 \\
\hline
\end{tabular}

Abbreviations: Sheight Standardized height, SSH Standardized siting height, Sweight Standardized weight, SWC Standardized waist circumference, SAST Standardized abdominal skinfold thickness, STG Standardized triacylglycerol, SBMI Standardized body mass index, SWHtR Standardized waist-height ratio, SInCLAP Standardized logarithmic children's lipid accumulation product, SRCLAP-H Standardized relative children's lipid accumulation product per height

\section{Discussion}

The prevalence of childhood hypertension has been increasing worldwide [30]. The current research showed that the overall prevalence of childhood hypertension was $5.7 \%$ (5.5\% for boys and $6.0 \%$ for girls), which was generally lower than that reported at the national level. According to a national survey, the prevalence of hypertension among 35,657 Chinese teenagers aged 17 years old was $12.4 \%$ ( $12.4 \%$ in boys and $12.3 \%$ in girls) [31]. Reports from the Chinese National Survey on Students' Constitution and Health $(\mathrm{CNSSCH})$ showed that the prevalence of elevated blood pressure among children in 2010 was $16.1 \%$ for boys and $12.9 \%$ for girls [32]. The reasons for the discrepancies may be regional and population differences in children's blood pressure distribution; alternatively, the diagnostic criteria, children's ages, and sample size in this study were different from other studies. A meta-analysis also found that the overall prevalence of hypertension among preschool children in China was only 5\% (95\% CI: 4\%, 9\%) [33]. In addition, this study found that there were no significant differences in moderate to strenuous physical activity time, sedentary activity time, healthy eating behaviors and unhealthy eating behaviors between children with hypertension and non-hypertensive children. Qu et al. [34] reported the consistent findings that physical activity intensity and dietary behavior management had nothing to do with the occurrence of hypertension in children. However, some studies also reported that an increase of physical activity intensity and time decreased the incidence of hypertension and that an unhealthy diet increased the risk of hypertension [35-37].

There is growing evidence that an increase of hypertension in children is closely related to weight gain [38].
$\mathrm{BMI}$ is an internationally recognized index for screening obesity. Previous studies showed that BMI was also associated with hypertension in children and adolescents [39-41]. In this study, it was found that the body weight and BMI in hypertensive children were significantly higher than those in non-hypertensive children. Although BMI provides a simple and convenient measure of obesity, it does not measure the distribution of body fat [42]. The mechanism of childhood obesity leading to hypertension is very complex [43]. It is worth noting that the functions of different adipose tissues are very different [44]. Some studies have pointed out that abdominal fat is more closely related to hypertension in children than BMI [45].

WC and WHtR can accurately reflect the degree of abdominal obesity. One study showed that an increase of WC in children with a normal weight was associated with an increase in blood pressure [46]. A study by Cruz et al. [47] showed that waistline was a good predictor of elevated blood pressure in children aged 8 to 10 years old. This study also found that the WC in hypertensive children was significantly higher than that in non-hypertensive children, and $\mathrm{SWC} \geq P_{75}$ significantly increased the risk of hypertension (OR $(95 \%$ CI): $2.21(1.13,4.30)$. Lo $\mathrm{K}$ et al. [48] reported that the WC was more closely associated with cardiac metabolism and hypertension in children compared with BMI, WC, and WHtR. Some researchers believe that WHtR is an important indicator of obesity and is more likely to predict cardiovascular risk than BMI [49]. In this study, we also found that there was a significant correlation between WHtR and hypertension in children, with an OR (95\% CI) of 2.64 (1.35, 5.14). Previous studies [23, 24] reported that children 
Table 2 Standardized differences in anthropmetric indexes, dietary behaviors and physical activity in children with hypertension and non-hypertension. $(n=683)$

\begin{tabular}{|c|c|c|c|c|c|}
\hline Variables & $\begin{array}{l}\text { Non-hypertension } \\
\text { Group }(n=644) \\
n(\%)\end{array}$ & $\begin{array}{l}\text { Hypertension } \\
\text { Group }(n=39) \\
n(\%)\end{array}$ & $x^{2}$ & $P$-value & OR $(95 \% \mathrm{Cl})$ \\
\hline \multicolumn{3}{|l|}{ Sex } & 0.09 & 0.766 & $0.91(0.48,1.73)$ \\
\hline Girls & 298(46.3) & $19(48.7)$ & & & \\
\hline Boys & $346(53.7)$ & $20(51.3)$ & & & \\
\hline \multicolumn{3}{|l|}{ Ages } & 3.14 & 0.077 & $1.78(0.93,3.41)$ \\
\hline $8 \sim$ & 405(62.9) & 19(48.7) & & & \\
\hline $12 \sim 15$ & 239(37.1) & 20(51.3) & & & \\
\hline \multicolumn{3}{|l|}{ Sheight } & 0.05 & 0.820 & $0.92(0.43,1.97)$ \\
\hline$<P_{75}$ & $485(75.3)$ & $30(76.9)$ & & & \\
\hline$\geq P_{75}$ & 159(24.7) & $9(23.1)$ & & & \\
\hline \multicolumn{3}{|l|}{$\mathrm{SSH}$} & 1.58 & 0.210 & $1.55(0.78,3.09)$ \\
\hline$<P_{75}$ & 487(75.6) & $26(66.7)$ & & & \\
\hline$\geq P_{75}$ & $157(24.4)$ & 13(33.3) & & & \\
\hline \multicolumn{3}{|l|}{ Sweight } & 4.18 & 0.041 & $1.99(1.02,3.89)$ \\
\hline$<P_{75}$ & $490(76.1)$ & $24(61.5)$ & & & \\
\hline$\geq P_{75}$ & 154(23.9) & $15(38.5)$ & & & \\
\hline \multicolumn{3}{|l|}{ SWC } & 5.51 & 0.019 & $2.18(1.12,4.22)$ \\
\hline$<P_{75}$ & $488(75.8)$ & $23(59.0)$ & & & \\
\hline$\geq P_{75}$ & $156(24.2)$ & $16(41.0)$ & & & \\
\hline \multicolumn{3}{|l|}{ SAST } & 15.64 & $<0.001$ & $3.50(1.82,6.73)$ \\
\hline$<P_{75}$ & 495(76.9) & 19(48.7) & & & \\
\hline$\geq P_{75}$ & 149(23.1) & $20(51.3)$ & & & \\
\hline \multicolumn{3}{|l|}{ STG } & 7.44 & 0.006 & $2.44(1.26,4.71)$ \\
\hline$<P_{75}$ & $489(75.9)$ & $22(56.4)$ & & & \\
\hline$\geq P_{75}$ & $155(24.1)$ & 17(43.6) & & & \\
\hline \multicolumn{3}{|l|}{ SBMI } & 5.63 & 0.018 & $2.20(1.13,4.26)$ \\
\hline$<P_{75}$ & 489(75.9) & $23(59.0)$ & & & \\
\hline$\geq P_{75}$ & 155(24.1) & $16(41.0)$ & & & \\
\hline \multicolumn{3}{|l|}{ SWHtR } & 7.74 & 0.005 & $2.48(1.28,4.79)$ \\
\hline$<P_{75}$ & $491(76.2)$ & $22(56.4)$ & & & \\
\hline$\geq P_{75}$ & 153(23.8) & 17(43.6) & & & \\
\hline \multicolumn{3}{|l|}{ SLnCLAP } & 21.98 & $<0.001$ & $4.34(2.24,8.38)$ \\
\hline$<P_{75}$ & $496(77)$ & 17(43.6) & & & \\
\hline$\geq P_{75}$ & $148(23)$ & $22(56.4)$ & & & \\
\hline \multicolumn{3}{|l|}{ SRCLAP H } & 22.57 & $<0.001$ & $4.41(2.28,8.53)$ \\
\hline$<P_{75}$ & 498(77.3) & 17(43.6) & & & \\
\hline$\geq P_{75}$ & $146(22.7)$ & $22(56.4)$ & & & \\
\hline \multicolumn{3}{|c|}{ Moderate-to-vigorous physical activity time } & 1.55 & 0.213 & $0.65(0.33,1.28)$ \\
\hline$<60 \min$ & $347(53.9)$ & $25(64.1)$ & & & \\
\hline$\geq 60 \mathrm{~min}$ & 297(46.1) & 14(35.9) & & & \\
\hline \multicolumn{3}{|c|}{ Sedentary activity time } & 2.05 & 0.153 & $1.63(0.83,3.19)$ \\
\hline$<120 \min$ & $307(47.7)$ & 14(35.9) & & & \\
\hline$\geq 120 \mathrm{~min}$ & $337(52.3)$ & $25(64.1)$ & & & \\
\hline
\end{tabular}


Table 2 Standardized differences in anthropmetric indexes, dietary behaviors and physical activity in children with hypertension and non-hypertension. ( $n=683$ ) (Continued)

\begin{tabular}{|c|c|c|c|c|c|}
\hline Variables & $\begin{array}{l}\text { Non-hypertension } \\
\text { Group }(n=644) \\
n(\%)\end{array}$ & $\begin{array}{l}\text { Hypertension } \\
\text { Group }(n=39) \\
n(\%)\end{array}$ & $x^{2}$ & $P$-value & OR $(95 \% \mathrm{Cl})$ \\
\hline Healthy dietary behaviors & & & 1.03 & 0.311 & $0.65(0.28,1.50)$ \\
\hline$<P_{75}$ & $482(74.8)$ & $32(82.1)$ & & & \\
\hline$\geq P_{75}$ & 162(25.2) & $7(17.9)$ & & & \\
\hline Risk dietary behaviors & & & 0.29 & 0.590 & $1.22(0.59,2.50)$ \\
\hline$<P_{75}$ & 487(75.6) & 28(71.8) & & & \\
\hline$\geq P_{75}$ & 157(24.4) & $11(28.2)$ & & & \\
\hline
\end{tabular}

Abbreviations: Sheight Standardized height, SSH standardized siting height, Sweight Standardized weight, SWC Standardized waist circumference, SAST Standardized abdominal skinfold thickness, STG Standardized triacylglycerol, SBMI Standardized body mass index, SWHtR Standardized waist-height ratio, SInCLAP Standardized logarithmic children's lipid accumulation product, SRCLAP-H Standardized relative children's lipid accumulation product per height

LAP was significant associated with hypertension or metabolic syndrome in Chinese children and adolescents as compared with BMI and WHtR.

This study found that BMI, WC, WHtR, and children LAP were significantly associated with hypertension in children, which is consistent with previous studies. However, BMI is limited to distinguishing the ratio of body fat to muscle tissue and not the distribution of body fat [19]. WC and WHtR can only show the accumulation of fat in the blood circulation

Table 3 The associations between different groups of anthropometric indexes and hypertension using logistic regressions

\begin{tabular}{lll}
\hline Variables & OR $(95 \% \mathrm{Cl})$ & $P$-value \\
\hline Sweight & & \\
$\quad \geq P_{75}$ & $1.99(1.02,3.91)$ & 0.045 \\
SWC & & \\
$\quad \geq P_{75}$ & $2.21(1.13,4.30)$ & 0.020 \\
SAST & & $<0.001$ \\
$\quad \geq P_{75}$ & $3.61(1.86,6.99)$ & \\
STG & & 0.009 \\
$\quad \geq P_{75}$ & $2.43(1.25,4.71)$ & 0.015 \\
SBMl & & \\
$\quad \geq P_{75}$ & $2.30(1.18,4.49)$ & 0.004 \\
SWHtR & & $<0.001$ \\
$\quad \geq P_{75}$ & $2.64(1.35,5.14)$ & $<0.001$ \\
SInCLAP & & \\
$\quad \geq P_{75}$ & $4.43(2.28,8.61)$ & \\
SRCLAP-H & & \\
$\quad \geq P_{75}$ & $4.49(2.31,8.71)$ &
\end{tabular}

Abbreviations: Sweight Standardized weight, SWC Standardized waist circumference, SAST Standardized abdominal skinfold thickness, STG Standardized triacylglycerol, SBMI Standardized body mass index, SWHtR Standardized waist-height ratio, SInCLAP Standardized logarithmic children's lipid accumulation product, SRCLAP-H Standardized relative children's lipid accumulation product per height
[50]. Children LAP only reflects the accumulation of adipose tissue and lipids in the blood circulation, while neglecting the accumulation of lipids per unit density of the human body.

The present study showed that SRCLAP-H in hypertensive children was significantly higher than it was in non-hypertensive children; SRCLAP-H $\geq P_{75}$ was significantly associated with an increased risk of hypertension (OR (95\% CI) was $4.49(2.31,8.71)$, which were higher than those of WC, BMI, WHtR, and children LAP, respectively). Therefore, compared with WC, BMI, WHtR, and children LAP, RCLAP-H was more strongly associated with hypertension on the basis of the same critical values. In addition, after adjusting for physical activity time and dietary behavior factors, the stepwise logistic model (forward conditional method) showed SRCLAP-H significantly increased risk of hypertension, while SWC, SBMI, SWHtR and SlnCLAP did not, which means RCLAP-H may be more strongly associated with hypertension than other indicators. We speculate that RCLAP may be more suitable for differential diagnosis of hypertension in children and adolescents. RCLAP-H reflects the accumulation of lipids per unit height. Children with the same children LAP but with a shorter height may have a higher risk of developing high blood pressure.

However, this study has some limitations. First, this was a cross-sectional study. Therefore, the causal relationship between RCLAP and hypertension cannot be inferred. Second, there is no biological or rationale for the calculation of RCLAP. In addition, this study used a self-administered food frequency questionnaire which has not been validated elsewhere. Blood pressure was measured only twice in this study, which could generate misclassification bias. 3 measurements and taking the average of the last 2 measurements would be ideal. Finally, we only studied Chinese children and adolescents, and the generalizability of our findings to other countries is limited and needs additional data for confirmation. 


\section{Conclusion}

In conclusion, it is crucial to assess visceral fat accumulation in a convenient and cheap way for the prevention of early CVD in children and adolescents. Compared with traditional obesity indicators such as BMI, WC and WHtR, RCLAP-H can better reflect the density of lipid accumulation per unit height among children and adolescents, rather than simple high body weight or abdominal fat thickness. Our study suggests that the relative children's lipid accumulation product (RCLAP-H) is associated with hypertension. As traditional assessment methods of visceral fat evaluation are not available in daily clinical application, RCLAP can be extensively used in epidemiological studies and some large-scale clinical trials. Due to the sample size in our study is limited, RCLAP also requires extensive population data screening to determine criteria for wider guidance in clinical practice.

\begin{abstract}
Abbreviations
SH: Standardized height; SSH: Standardized sitting height; Sweight: Standardized weight; WC: Waist circumference; SWC: Standardized waist circumference; AST: Abdominal skinfold thickness; SAST: Standardized abdominal skinfold thickness; TG: Triglycerides; STG: Standardized triglycerides; BMI: Body mass index; SBMI: Standardized body mass index; WHtR: Waist-height ratio; SWHtR: Standardized Waist-height ratio; CVD: Cardiovascular disease; SBP: Systolic blood pressure; DBP: Diastolic blood pressure; LAP: Lipid accumulation product; Children LAP: Children's lipid accumulation product; SInCLAP: Standardized logarithmic children's lipid accumulation product; RCLAP-H: Relative children's lipid accumulation product per height; SRCLAP-H: Standardized relative children's lipid accumulation product per height
\end{abstract}

\section{Acknowledgments}

The authors would like to thank the students who participated in the current study.

\section{Authors' contributions}

$\mathrm{ZZ}$ collected and analyzed the data and prepared the first draft of the manuscript. LZ and LS analyzed and collected the data. BW and YY collected the data and revised the manuscript. HG and LF conceived and designed the research and revised the manuscript. All authors reviewed the manuscript. All authors read and approved the final manuscript.

\section{Funding}

This project was supported by grants from the National Natural Science Foundation of China (No.81502823), Excellent Young Talents Fund Program of Higher Education Institutions of Anhui Province (No.gxyqZD2017063), 512 Talent Cultivation Plan of Bengbu Medical College (by51201204), 2020 Outstanding Young Backbone Talents in Colleges and Universities Overseas Visiting and Training Project (by15200053) and Innovative Team Project of Natural Science Category of Bengbu Medical College (BYKC201901)

\section{Availability of data and materials}

The datasets used and/or analysed during the current study are available from the corresponding author on reasonable request.

\section{Declarations}

\section{Ethics approval and consent to participate}

The study was conducted in accordance with the Declaration of Helsinki (as revised in 2013). The present study was approved by the Medical Ethics Committee of Bengbu Medical College [2015 No. 003] and informed consent was taken from all the participants (or their parents) before the survey.
Consent for publication

Not applicable.

\section{Competing interests}

The authors declare that they have no competing interests.

Received: 9 April 2021 Accepted: 24 September 2021

Published online: 19 October 2021

\section{References}

1. Brody AM, Kumar VA, Levy PD. Hot topic: global burden of treating hypertension-what is the role of the emergency department? Curr Hypertens Rep. 2017;19(1):8. https://doi.org/10.1007/s11906-017-0707-4

2. Tadic M, Cuspidi C, Hering D. Hypertension and cognitive dysfunction in elderly: blood pressure management for this global burden. BMC Cardiovasc Disord. 2016;16(1):208. https://doi.org/10.1186/s12872-016-03860 .

3. Ingelfinger JR. The child or adolescent with elevated blood pressure. N Engl J Med. 2014;371(11):1075. https://doi.org/10.1056/NEJMc1408238.

4. Okpokowuruk FS, Akpan MU, Ikpeme EE. Prevalence of hypertension and prehypertension among children and adolescents in a semi-urban area of Uyo Metropolis, Nigeria. Pan Afr Med J. 2017;28:303. https://doi.org/10.11 604/pamj.2017.28.303.14396.

5. Samuels JA, Zavala AS, Kinney JM, Bell CS. Hypertension in children and adolescents. Adv Chronic Kidney Dis. 2019;26(2):146-50. https://doi.org/10.1 053/j.ackd.2019.02.003

6. Zou Y, Xia N, Zou Y, Chen Z, Wen Y. Smartphone addiction may be associated with adolescent hypertension: a cross-sectional study among junior school students in China. BMC Pediatr. 2019;19(1):310. https://doi. org/10.1186/s12887-019-1699-9.

7. Dong Y, Ma J, Song Y, Ma Y, Dong B, Zou Z, et al. Secular trends in blood pressure and overweight and obesity in Chinese boys and girls aged 7 to 17 years from 1995 to 2014. Hypertension. 2018;72(2):298-305. https://doi. org/10.1161/HYPERTENSIONAHA.118.11291.

8. Xi B, Liang Y, Mi J. Hypertension trends in Chinese children in the national surveys, 1993 to 2009. Int J Cardiol. 2013;165(3):577-9. https://doi.org/10.101 6/j.ijcard.2012.09.032

9. Chrysaidou K, Chainoglou A, Karava V, Dotis J, Printza N, Stabouli S. Secondary hypertension in children and adolescents: novel insights. Curr Hypertens Rev. 2020;16(1):37-44. https://doi.org/10.2174/15734021156661 90416152820.

10. Marcon D, Tagetti A, Fava C. Subclinical organ damage in children and adolescents with hypertension: current guidelines and beyond. High Blood Press Cardiovasc Prev. 2019;26(5):361-73. https://doi.org/10.1007/s40292-01 9-00345-1.

11. Patel A, Bharani A, Sharma M, Bhagwat A, Ganguli N, Chouhan DS. Reply: prevalence of hypertension and prehypertension in schoolchildren from Central India. Ann Pediatr Cardiol. 2019;12(3):349. https://doi.org/10.4103/a pc.APC_90_19.

12. Hope KD, Zachariah JP. Predictors and consequences of pediatric hypertension: have advanced echocardiography and vascular testing arrived? Curr Hypertens Rep. 2019;21(7):54. https://doi.org/10.1007/s11906019-0958-3.

13. Urbina EM, Khoury PR, Bazzano L, Burns TL, Daniels S, Dwyer T, et al. Relation of blood pressure in childhood to self-reported hypertension in adulthood. Hypertension. 2019;73(6):1224-30. https://doi.org/10.1161/ HYPERTENSIONAHA.118.12334.

14. McCracken E, Monaghan M, Sreenivasan S. Pathophysiology of the metabolic syndrome. Clin Dermatol. 2018;36(1):14-20. https://doi.org/10.101 6/j.clindermatol.2017.09.004.

15. Carmienke S, Freitag MH, Pischon T, Schlattmann P, Fankhaenel T, Goebel H, et al. General and abdominal obesity parameters and their combination in relation to mortality: a systematic review and meta-regression analysis. Eur J Clin Nutr. 2013;67(6):573-85. https://doi.org/10.1038/ejcn.2013.61.

16. Peer N, Lombard C, Steyn K, Levitt N. Waist-to-height ratio is a useful indicator of cardio-metabolic risk in South Africa. Fam Pract. 2020;37(1):3642. https://doi.org/10.1093/fampra/cmz044.

17. Mi SQ, Yin P, Hu N, Li JH, Chen XR, Chen B, et al. BMI, WC, WHtR, VFI and $\mathrm{BFI}$ : which indictor is the most efficient screening index on type 2 diabetes in Chinese community population. Biomed Environ Sci. 2013;26(6):485-91. https://doi.org/10.3967/0895-3988.2013.06.009. 
18. Halperin RO, Sesso HD, Ma J, Buring JE, Stampfer MJ, Gaziano JM. Dyslipidemia and the risk of incident hypertension in men. Hypertension. 2006;47(1):45-50. https://doi.org/10.1161/01.HYP.0000196306.42418.0e.

19. Kahn HS. The "lipid accumulation product" performs better than the body mass index for recognizing cardiovascular risk: a population-based comparison. BMC Cardiovasc Disord. 2005;5(1):26. https://doi.org/10.1186/14 71-2261-5-26.

20. Wakabayashi I. Associations of blood lipid-related indices with blood pressure and pulse pressure in middle-aged men. Metab Syndr Relat Disord. 2015;13(1):22-8. https://doi.org/10.1089/met.2014.0093.

21. Song J, Zhao Y, Nie S, Chen X, Wu X, Mi J. The effect of lipid accumulation product and its interaction with other factors on hypertension risk in Chinese Han population: a cross-sectional study. PLoS One. 2018;13(6): e0198105. https://doi.org/10.1371/journal.pone.0198105.

22. Gao X, Wang G, Wang A, Xu T, Tong W, Zhang Y. Comparison of lipid accumulation product with body mass index as an indicator of hypertension risk among Mongolians in China. Obes Res Clin Pract. 2013; 7(4):e308-14. https://doi.org/10.1016/j.orcp.2012.02.002.

23. Wang $Y$, Liu W, Sun L, Zhang Y, Wang B, Yuan Y, et al. A novel indicator, childhood lipid accumulation product, is associated with hypertension in Chinese children and adolescents. Hypertens Res. 2020;43(4):305-12. https:// doi.org/10.1038/s41440-019-0366-8.

24. Zhang Y, Hu J, Li Z, Li T, Chen M, Wu L, et al. A novel Indicator of lipid accumulation product associated with metabolic syndrome in Chinese children and adolescents. Diabetes Metab Syndr Obes. 2019;12:2075-83. https://doi.org/10.2147/DMSO.S221786.

25. Huang YJ, Wong SH, Salmon J. Reliability and validity of the modified Chinese version of the Children's leisure activities study survey (CLASS) questionnaire in assessing physical activity among Hong Kong children. Pediatr Exerc Sci. 2009;21(3):339-53. https://doi.org/10.1123/pes.21.3.339.

26. Santos R, Zhang Z, Pereira JR, Sousa-Sa E, Cliff DP, Okely AD. Compliance with the Australian 24-hour movement guidelines for the early years: associations with weight status. BMC Public Health. 2017;17(Suppl 5):867. https://doi.org/10.1186/s12889-017-4857-8

27. Villagran Perez S, Novalbos-Ruiz JP, Rodriguez-Martin A, Martinez-Nieto JM, Lechuga-Sancho AM. Implications of family socioeconomic level on risk behaviors in child-youth obesity. Nutr Hosp. 2013;28(6):1951-60. https://doi. org/10.3305/nutrhosp.v28in06.6848.

28. Huo JK, Zhou LJ, Wen B, Wang XJ, Dong B, Ma J. The method of blood pressure evaluation among children and adolescents aged 7 to 17 years old in China. Zhonghua Yu Fang Yi Xue Za Zhi. 2019;53(12):1299-304. https:// doi.org/10.3760/cma.j.issn.0253-9624.2019.12.018.

29. Zhai Y, Li WR, Shen C, Qian F, Shi XM. Prevalence and correlates of elevated blood pressure in Chinese children aged 6-13 years: a Nationwide School-based survey. Biomed Environ Sci. 2015;28(6):401-9. https://doi.org/10.3967/bes2015.057.

30. Flynn J. The changing face of pediatric hypertension in the era of the childhood obesity epidemic. Pediatr Nephrol. 2013;28(7):1059-66. https:// doi.org/10.1007/s00467-012-2344-0.

31. Yu D, Xu X, Gao X, Fang H, Ju L, Guo H, et al. Status of blood pressure and prevalence of hypertension among 6-17 years old children and adolescents in 2010-2012 in China. Wei Sheng Yan Jiu. 2018;47(1):1-6.

32. Dong B, Ma J, Wang HJ, Wang ZQ. The association of overweight and obesity with blood pressure among Chinese children and adolescents. Biomed Environ Sci. 2013;26(6):437-44. https://doi.org/10.3967/0895-3988.2013.06.004.

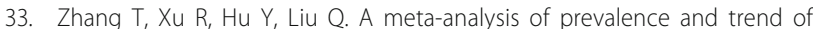
hypertension in preschool children in China. Occup Health. 2019;35(04): 541-5.

34. Qu Z, Parry M, Liu F, Wen X, Li J, Zhang Y, et al. Self-management and blood pressure control in China: a community-based multicentre crosssectional study. BMJ Open. 2019;9(3):e025819. https://doi.org/10.1136/ bmjopen-2018-025819.

35. Ruiz LD, Zuelch ML, Dimitratos SM, Scherr RE. Adolescent Obesity: Diet Quality, Psychosocial Health, and Cardiometabolic Risk Factors. Nutrients. 2019;12(1). https://doi.org/10.3390/nu12010043.

36. Keung V, Lo K, Cheung C, Tam W, Lee A. Changes in dietary habits and prevalence of cardiovascular risk factors among school students in Macao, China. Obes Res Clin Pract. 2019;13(6):541-7. https://doi.org/10.1016/j.orcp.2 019.10.007.

37. Morales Suarez-Varela M, Mf MC, Soler Quiles C, Llopis-Morales A, PeraitaCosta I, Llopis-Gonzalez A. Prevalence of arterial hypertension and its association with anthropometry and diet in children (6 to 9 years old):
ANIVA study. Nutr Hosp. 2019;36(1):133-41. https://doi.org/10.20960/nh.021 05.

38. Zhang Q, Yang L, Zhang Y, Zhao M, Liang Y, Xi B. Hypertension prevalence based on three separate visits and its association with obesity among Chinese children and adolescents. Front Pediatr. 2019;7:307. https://doi. org/10.3389/fped.2019.00307.

39. Wang J, Zhu Y, Jing J, Chen Y, Mai J, Wong SH, et al. Relationship of BMI to the incidence of hypertension: a 4 years' cohort study among children in Guangzhou, 2007-2011. BMC Public Health. 2015;15(1):782. https://doi.org/1 0.1186/s12889-015-1997-6.

40. Hu J, Chu GP, Huang FF, Zhou YK, Teng CG, Yang HB, et al. Relation of body mass index (BMI) to the prevalence of hypertension in children: a 3years' school-based prospective study in Suzhou, China. Int J Cardiol. 2016;222: 270-4. https://doi.org/10.1016/j.ijcard.2016.07.217.

41. Kuciene R, Dulskiene V. Associations between body mass index, waist circumference, waist-to-height ratio, and high blood pressure among adolescents: a cross-sectional study. Sci Rep. 2019;9(1):9493. https://doi.org/1 0.1038/s41598-019-45956-9.

42. Rivera-Soto WT, Rodriguez-Figueroa L. Is waist-to-height ratio a better obesity risk-factor Indicator for Puerto Rican children than is BMI or waist circumference? P R Health Sci J. 2016;35(1):20-5.

43. Raj M, Krishnakumar R. Hypertension in children and adolescents: epidemiology and pathogenesis. Indian J Pediatr. 2013;80(Suppl 1):S71-6. https://doi.org/10.1007/s12098-012-0851-4.

44. Hoffstedt J, Arner E, Wahrenberg H, Andersson DP, Qvisth V, Lofgren P, et al. Regional impact of adipose tissue morphology on the metabolic profile in morbid obesity. Diabetologia. 2010;53(12):2496-503. https://doi.org/10.1007/ s00125-010-1889-3.

45. Pirimoglu B, Sade R, Islek A, Kantarci M. The liver fat fraction and abdominal subcutaneous and visceral fat volume distribution in Normal-weight, overweight, and obese children using a new magnetic resonance imaging technique. J Comput Assist Tomogr. 2019;43(2):194-9. https://doi.org/10.1 097/RCT.0000000000000803.

46. Pazin DC, Rosaneli CF, Olandoski M, Oliveira ERN, Baena CP, Figueredo AS, et al. Waist circumference is associated with blood pressure in children with Normal body mass index: a cross-sectional analysis of 3,417 school children. Arq Bras Cardiol. 2017;109(6):509-15. https://doi.org/10.5935/abc.20170162.

47. Cruz NRC, Cardoso PC, Frossard T, Ferreira FO, Brener S, Gomides AFF, et al. Waist circumference as high blood pressure predictor in school age children. Cien Saude Colet. 2019;24(5):1885-93. https://doi.org/10.1 590/1413-81232018245.18012017.

48. Lo K, Wong M, Khalechelvam P, Tam W. Waist-to-height ratio, body mass index and waist circumference for screening paediatric cardio-metabolic risk factors: a meta-analysis. Obes Rev. 2016;17(12):1258-75. https://doi.org/1 0.1111/obr.12456.

49. Mehta SK. Waist circumference to height ratio and left ventricular mass in children and adolescents. Cardiol Young. 2016;26(4):658-62. https://doi. org/10.1017/S1047951115000803.

50. Liu C, Zhang L. Research progress of new type body fat indexes of lipid accumulation product index and visceral adiposity index. Chin J Diabetes. 2016;24(11):1032-5.

\section{Publisher's Note}

Springer Nature remains neutral with regard to jurisdictional claims in published maps and institutional affiliations.

Ready to submit your research? Choose BMC and benefit from:

- fast, convenient online submission

- thorough peer review by experienced researchers in your field

- rapid publication on acceptance

- support for research data, including large and complex data types

- gold Open Access which fosters wider collaboration and increased citations

- maximum visibility for your research: over $100 \mathrm{M}$ website views per year

At $\mathrm{BMC}$, research is always in progress.

Learn more biomedcentral.com/submissions 